\title{
Natural course and prognostic factors of chronic urticaria in Korean children: A single center experience
}

\author{
Hwanhee Park, ${ }^{1 *}$ Ji Young Lee, ${ }^{2 *}$ Ari Song, ${ }^{1}$ Minyoung Jung, ${ }^{1,3}$ Minji Kim,${ }^{4}$ Insuk Sohn,,${ }^{5}$ MinJi Kim,${ }^{5}$ Joongbum Cho, ${ }^{1}$ \\ Kangmo Ahn, ${ }^{1,3}$ Jihyun Kim ${ }^{1,3}$
}

\begin{abstract}
Background: Chronic urticaria (CU) has an adverse effect on academic achievement and psychosocial development in children.

Objective: We aimed to investigate the natural course of $\mathrm{CU}$ and to identify relevant factors associated with a poor CU prognosis in Korean children.

Methods: We retrospectively analyzed 253 children with episodes of wheals or angioedema at least 3 times a week that persisted for at least 6 weeks. Clinical data and laboratory results were obtained from medical records and parental telephone interviews. Kaplan-Meier survival analysis and log rank tests were performed to assess the median time to remission of CU and prognostic factors.

Results: Median age at onset was 5.0 years (interquartile range, 2.5-9.1) and median follow-up period was 7.6 months (interquartile range, 3.9-19.7). Of 253 patients, $68.8 \%$ had chronic inducible urticaria and $31.2 \%$ had chronic spontaneous urticaria. Physical urticaria was the only cause of chronic inducible urticaria, and the most common physical urticaria was dermographism. Median duration to remission of CU was 10.2 months (95\% confidence intervals, 8.0-12.5 months). Kaplan-Meier analysis revealed that $33.4 \%, 53.0 \%$, and $71.2 \%$ of children were in remission at 6,12 , and 24 months, respectively, after the onset of CU. The presence of allergic sensitization was significantly associated with a poor CU prognosis in univariable and multivariable analyses $(P=0.010$ and $P=0.014$, respectively).
\end{abstract}

Conclusion: Half of children with CU were in remission 10.2 months after onset. Allergic sensitization was a risk factor associated with longer duration CU.

Keywords: Chronic urticaria; Etiology; Prognosis; Children; Korea

\footnotetext{
From:

${ }^{1}$ Department of Pediatrics, Samsung Medical Center, Sungkyunkwan University School of Medicine, Seoul, Korea

2 Department of Pediatrics, Hallym University Hangang Sacred Heart Hospital, Seoul, Korea

Environmental Health Center for Atopic Diseases, Samsung Medical Center, Seoul, Korea

${ }^{4}$ Department of Pediatrics, Hallym University Dongtan Sacred Heart Hospital, Hallym University School of Medicine, Dongtan, Gyeonggi-do, Korea

Statistics and Data Center, Research Institute for Future Medicine, Samsung Medical Center, Seoul, Korea

* These authors contributed equally to this work.
}

\section{Corresponding author:}

Jihyun Kim

Department of Pediatrics, Samsung Medical Center, Sungkyunkwan

University School of Medicine, 81 Irwon-ro, Gangnam-gu, Seoul, 06351,

Korea

E-mail: jhlovechild@gmail.com

\section{Introduction}

Chronic urticaria (CU) is defined as wheals with recurrent episodes lasting for at least 6 weeks. The prevalence of CU has been reported to be $0.5-5.0 \%$ in the general population and about $0.1-0.3 \%$ in children. ${ }^{1}$ It is known that children have a lower prevalence than adults. ${ }^{1}$ Impairment of quality of life in patients with $\mathrm{CU}$ is comparable to that experienced by patients with other chronic diseases such as ischemic heart disease, cystic fibrosis, and epilepsy. ${ }^{2,3}$ CU impairs physical activity and lowers social function, which can adversely affect academic achievement and psychosocial development in children and adolescents. ${ }^{3-5}$

Acute urticaria is frequently associated with identifiable causes; in contrast, it is difficult to identify the etiology and to predict the occurrence or exacerbation of symptoms in patients with CU. ${ }^{3,6} \mathrm{CU}$ is classified into chronic spontaneous urticaria (CSU) and chronic inducible urticaria (CIU) according to 
whether symptoms occur spontaneously or are induced by specific triggers. Although its pathogenesis is poorly understood, mixed Th1/Th2 immune response, mast cell activation, and autoimmunity are considered to play a role in the pathogenic mechanisms of CU. ${ }^{7}$ There are also several types of evidence supporting that autoantigen is synthesized by specific triggers leading to mast cell degranulation in patients with CIU. $^{8,9}$ In general, the duration of CSU is $1-5$ years, but is likely to be longer in more severe cases..$^{10} \mathrm{~A}$ previous Korean study reported that the mean duration of CU was 3.76 years in 641 adults. ${ }^{11}$ The co-existence of angioedema, severity, and the presence of anti-thyroid antibodies were associated with longer disease duration in adult patients with CU. ${ }^{12,13}$ However, few studies have investigated the clinical course or identified prognostic factors of CU in children.

Providing correct information about the etiology and prognosis of CU can reduce the anxiety of pediatric patients and their parents and help establish a therapeutic plan. Therefore, our aims in this study were to investigate the clinical features and natural course of CU and to identify factors associated with a poor CU prognosis in Korean children.

\section{Methods \\ Patients}

We retrospectively reviewed the medical records of patients 18 years or younger that were diagnosed with CU in Samsung Medical Center from January 2007 to October 2015. The definition of CU was wheals or angioedema that had lasted for more than 6 weeks and that occurred repeatedly (more than 3 times a week).

Demographic and clinical data were collected, including gender, age at onset, duration and frequency of symptoms, extent of skin involvement, presence of angioedema, and personal and familial history of allergic or autoimmune diseases. A family history of allergic diseases was defined as the presence of one or more family members diagnosed with atopic dermatitis, asthma, or allergic rhinitis by a physician.

All patients were interviewed using a detailed questionnaire regarding trigger factors such as sunlight, cold, water, pressure, vibration, exercise, scratching, foods, and drugs. Food or drug allergy was defined as a convincing history of reproducible symptoms within two hours after exposure to a single food or drug. Physical urticaria was diagnosed according to the criteria described by the Joint Task Force on Practice Parameters. ${ }^{14}$ In addition, medication use for CU (H1 receptor antagonists, $\mathrm{H} 2$ receptor antagonists, leukotriene antagonists, oral corticosteroids, immunosuppressants, and biologic agents) was investigated.

For patients who did not have data regarding remission of clinical symptoms on their medical chart, a telephone survey was utilized based on a preformulated questionnaire. Complete remission of $\mathrm{CU}$ was defined as the absence of urticaria for at least 4 weeks without any medication. ${ }^{13}$ This study was approved by the Institutional Review Board (IRB) of Samsung Medical Center (IRB No.2015-06-188).

\section{Laboratory test}

Eosinophils in peripheral blood, erythrocyte sedimentary rate (ESR), thyroid stimulating hormone (TSH), free thyroxine (T4), triiodothyronine (T3), thyroid auto-antibodies (thyroglobulin antibody, antimicrosomal antibody, and TSH receptor antibody), antinuclear antibody (ANA), serum C-reactive protein (CRP) levels, and serum total immunoglobulin E (IgE) levels were measured. The ANA test was performed by using the indirect immunofluorescence method with sera (Fluoro Hepana Test, MBL, Nagoya, Japan). Skin prick tests (Allergopharma, Reinbek, Germany) on the back or measurement of specific IgE levels with the immunoCAP system (Thermo Fisher Scientific Inc., Waltham, MA, USA) were performed regarding the following common allergens: Dermatophagoides pteronyssinus, D. farinae, egg white, cow's milk, wheat, soybean, and peanut. Positive sensitization was defined as a wheal diameter $\geq 3 \mathrm{~mm}$ or specific IgE levels $\geq 0.35 \mathrm{kU} / \mathrm{L}$. Eosinophilia was defined as when eosinophils comprised more than $4 \%$ of total leukocytes.

\section{Statistical analysis}

Data for continuous variables were shown as median and interquartile range. Prevalence rates were shown as percentages. Cumulative survival curves were estimated by the Kaplan -Meier method, and relationships between the cumulative probability of complete remission of $\mathrm{CU}$ and prognostic factors were analyzed using a log-rank test. The influence of prognostic factors on remission was evaluated by univariable Cox regression analyses. The relative importance of multiple prognostic factors on CU remission was analyzed using multivariable analysis in conjunction with the Cox proportional regression model. Variables with a $P$ value of less than 0.2 in univariable analysis were chosen for multivariable analysis. Candidate variables for adjustment included gender, age at onset ( $<5$ years old or $\geq 5$ years old), clinical symptoms (with or without angioedema), past history of allergic diseases (presence or absence), past history of autoimmune diseases (presence or absence), family history of allergic diseases (presence or absence), inducible factors (presence or absence), sensitization (negative or positive), total $\operatorname{IgE}(<200 \mathrm{kU} / \mathrm{L}$ or $\geq 200 \mathrm{kU} / \mathrm{L})$, eosinophils $(<4 \%$ or $\geq 4 \%)$, ESR $(<20 \mathrm{~mm} / \mathrm{hr}$ or $\geq 20 \mathrm{~mm} / \mathrm{hr}$ ), CRP $(<0.5 \mathrm{mg} / \mathrm{dl}$ or $\geq 0.5 \mathrm{mg} / \mathrm{dl})$, and ANA (negative or positive). CRP and ANA were excluded from the multivariate analysis because data were available for only 80 and 88 cases, respectively. Statistical analyses were performed using SAS (version 9.3, SAS Institute, Inc., Cary, NC, USA). Statistical significance was defined as a $P$ value $<0.05$.

\section{Results}

A total of 253 patients (142 boys and 111 girls) with CU were included in this study. Median age at onset was 5.0 years (interquartile range, 2.5-9.1) and median follow-up period was 7.6 months (interquartile range, 3.9-19.7 months) (Table 1). Overall, 29 (11.5\%) patients had wheals accompanied with angioedema, while 224 (88.5\%) patients had wheals only without angioedema. Of 253 patients, 68.8\% (174/253) had CIU, while $31.2 \%(79 / 253)$ had CSU. The only cause of 174 patients with CIU was physical urticaria, and the most common physical urticaria was dermographism $(128 / 174,73.6 \%)$, followed by cholinergic urticaria $(76 / 174,43.7 \%)$, cold urticaria $(15 / 174$, 
Table 1. Subject characteristics and laboratory results $(\mathbf{n}=$ 253).

\begin{tabular}{|lc}
\hline Characteristic & Number (\%) \\
\hline Gender & \\
Male & $142(56.1)$ \\
Female & $111(43.9)$ \\
\hline Age (years) & \\
$<1$ & $5.0(2.5-9.1)$ \\
$1-4$ & $15(5.9)$ \\
$5-9$ & $111(43.9)$ \\
$\geq 10$ & $78(30.8)$ \\
Clinical symptoms & $49(19.4)$ \\
Wheals only & \\
Angioedema with wheals & $224(88.5)$ \\
\hline Past medical history & $29(11.5)$ \\
Atopic dermatitis & \\
Allergic rhinitis & $52(20.1)$ \\
Asthma & $38(15.0)$ \\
Autoimmune disease & $24(9.5)$ \\
\hline Family history of allergic diseases & $7(2.8)$ \\
Atopic dermatitis & \\
Allergic rhinitis & $20(7.9)$ \\
Asthma & $38(15.0)$ \\
\hline Allergic sensitization ${ }^{* *}$ & $8(3.2)$ \\
\hline Log(total IgE, kU/L) & $90 / 219(41.1)$ \\
\hline
\end{tabular}

${ }^{*}$ Data are presented as medians (interquartile range).

** 219 patients underwent either a skin prick test or ImmunoCAP test.

$8.6 \%)$, delayed pressure urticaria $(9 / 174,5.2 \%)$, solar urticaria $(3 / 174,1.7 \%)$, and aquagenic urticaria $(2 / 174,1.1 \%)$.

Twenty-two (25.0\%) of 88 patients who underwent testing for ANA were positive. However, only one of these 22 patients had a history of autoimmune diseases such as systemic lupus erythematosus. TSH was elevated in only one of the 50 patients (2.0\%) who underwent a thyroid function test, but her T3 and free T4 levels were normal.

During the observation period, 195 (77.0\%) children had complete remission. In Kaplan-Meier survival analysis, 33.4\%, $53.0 \%$, and $71.2 \%$ of patients recovered at 6,12 , and 24 months after symptom onset, respectively (Figure 1). The median duration of CU was 10.2 months (95\% confidence intervals, 8.0-12.5 months). A total of 190 patients (75.1\%) were treated with $\mathrm{H} 1$ receptor antagonist alone, while 50 patients (19.8\%) received two $\mathrm{H} 1$ receptor antagonists or more. In addition, nine patients (3.6\%) were treated with both $\mathrm{H} 1$ and $\mathrm{H} 2$ receptor antagonists, and 21 patients $(8.3 \%)$ were treated with an $\mathrm{H} 1$ receptor antagonist as well as a leukotriene receptor antagonist. No patients required systemic corticosteroids for $\geq 3$ consecutive days or anti-IgE treatment.

Univariable analysis showed that patients who did not have inducible factors (CSU) or were not sensitized to common allergens had a better prognosis than those who had CIU or were sensitized to allergens ( $P=0.021$ and $P=0.010$, respectively) (Table 2). In Kaplan-Meier survival analysis, 40.7\%, 60.9\%, and $78.3 \%$ of CSU recovered at 6,12 , and 24 months after symptom onset, respectively. In addition, $29.4 \%, 49.4 \%$, and $67.8 \%$ of CIU patients recovered at 6,12 , and 24 months,

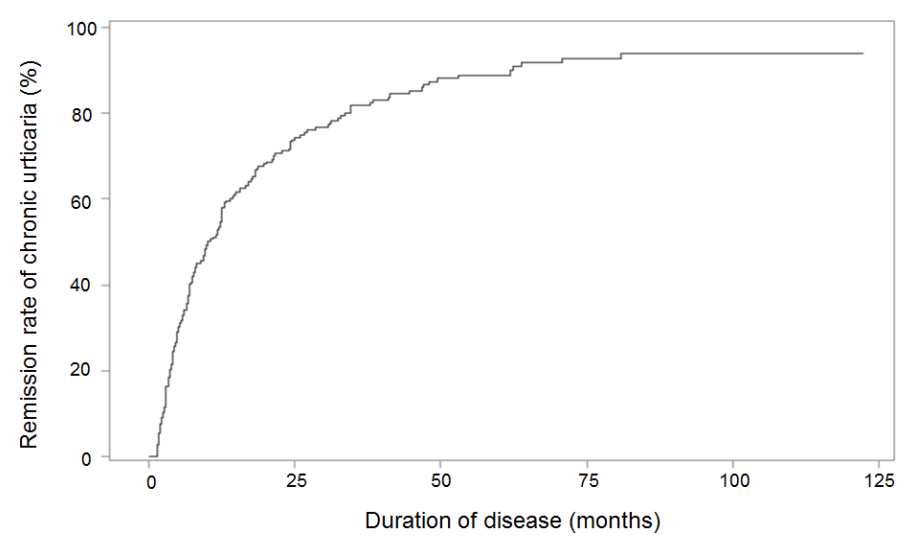

Figure 1. Kaplan-Meier survival analysis of children with chronic urticaria. Remission percentages at 6,12 , and 24 months after symptom onset were $33.4 \%, 53.0 \%$, and $71.2 \%$, respectively.

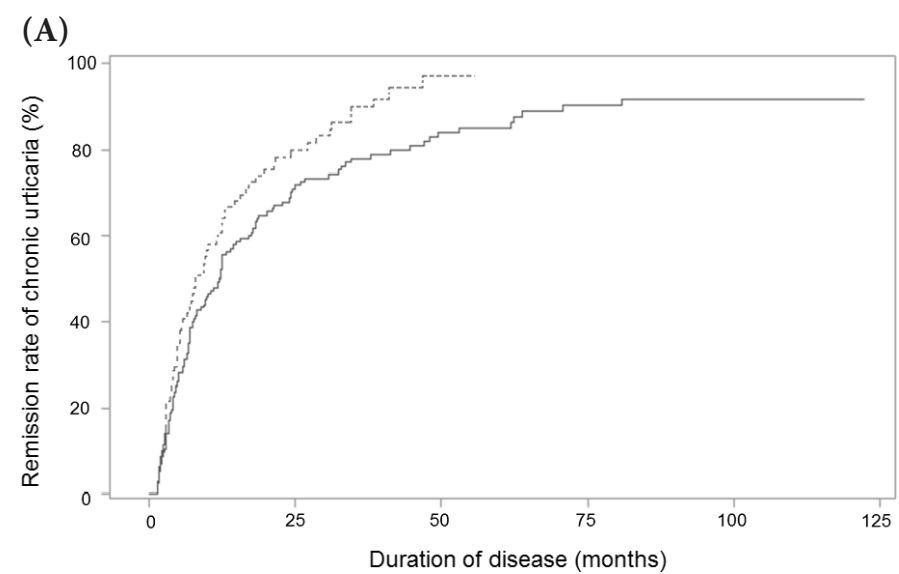

(B)

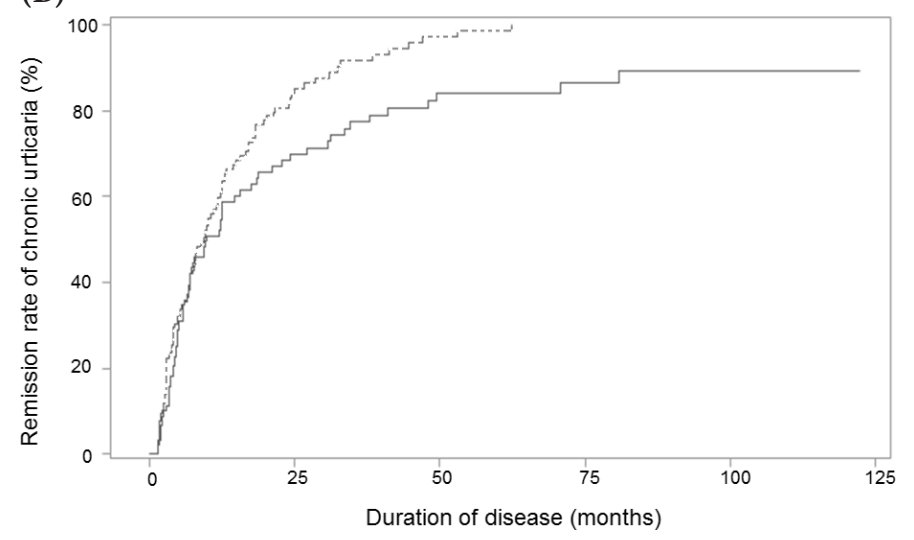

Figure 2. (A) Kaplan-Meier analysis of CIU (solid line) and CSU patients (dashed line). (B) Kaplan-Meier analysis of CU patients sensitized (solid line) and non-sensitized (dashed line) to allergens. CIU: chronic inducible urticaria, CSU: chronic spontaneous urticaria, CU: chronic urticaria.

respectively (Figure 2). Median disease duration was 8.0 months for children with CSU and 12.1 months for those with CIU, and 9.4 months for non-sensitized patients and 9.8 months for sensitized patients. Median recovery time was 9.6 months for boys, 10.8 months for girls, 9.6 months for younger children ( $<5$ years old), and 12.0 months for older children $(\geq 5$ years 
Table 2. Predictors of remission of chronic urticaria according to univariable and multivariable Cox analyses.

\begin{tabular}{|c|c|c|c|c|c|c|}
\hline \multirow{2}{*}{ Variables } & \multicolumn{3}{|c|}{ Univariable analysis } & \multicolumn{3}{|c|}{ Multivariable analysis } \\
\hline & $\begin{array}{c}\text { Hazard } \\
\text { ratio }\end{array}$ & $95 \%$ CI & $\begin{array}{c}P \\
\text { Value }\end{array}$ & $\begin{array}{c}\text { Hazard } \\
\text { ratio }\end{array}$ & $95 \%$ CI & $\begin{array}{c}P \\
\text { Value }\end{array}$ \\
\hline \multicolumn{7}{|l|}{ Gender } \\
\hline Female & 1 & & & & & \\
\hline Male & 0.945 & $(0.712-1.255)$ & 0.697 & & & \\
\hline \multicolumn{7}{|l|}{ Age } \\
\hline$<5$ years & 1 & & & 1 & & \\
\hline$\geq 5$ years & 1.276 & $(0.962-1.692)$ & 0.092 & 1.006 & $(0.740-1.366)$ & 0.970 \\
\hline \multicolumn{7}{|l|}{ Clinical symptoms } \\
\hline Wheals only & 1 & & & 1 & & \\
\hline Angioedema with wheals & 1.383 & $(0.861-2.222)$ & 0.180 & 1.393 & $(0.837-2.320)$ & 0.202 \\
\hline \multicolumn{7}{|l|}{ Past history of allergic diseases } \\
\hline No & 1 & & & & & \\
\hline Yes & 1.171 & $(0.879-1.563)$ & 0.281 & & & \\
\hline \multicolumn{7}{|c|}{ Past history of autoimmune diseases } \\
\hline No & 1 & & & 1 & & \\
\hline Yes & 2.451 & $(0.907-6.623)$ & 0.077 & 1.698 & $(0.520-5.556)$ & 0.381 \\
\hline \multicolumn{7}{|l|}{ Family history of allergic diseases } \\
\hline No & 1 & & & & & \\
\hline Yes & 1.068 & $(0.770-1.479)$ & 0.693 & & & \\
\hline \multicolumn{7}{|l|}{ Inducible factors } \\
\hline No & 1 & & & 1 & & \\
\hline Yes & 1.422 & $(1.054-1.919)$ & 0.021 & 1.330 & $(0.965-1.835)$ & 0.081 \\
\hline \multicolumn{7}{|l|}{ Sensitization } \\
\hline Negative & 1 & & & 1 & & \\
\hline Positive & 1.511 & $(1.104-2.070)$ & 0.010 & 1.486 & $(1.083-2.037)$ & 0.014 \\
\hline \multicolumn{7}{|l|}{ Total IgE } \\
\hline$<200 \mathrm{kU} / \mathrm{L}$ & 1 & & & & & \\
\hline$\geq 200 \mathrm{kU} / \mathrm{L}$ & 1.093 & $(0.791-1.511)$ & 0.590 & & & \\
\hline \multicolumn{7}{|l|}{ Eosinophils } \\
\hline$<4 \%$ & 1 & & & & & \\
\hline$\geq 4 \%$ & 1.059 & $(0.756-1.486)$ & 0.737 & & & \\
\hline \multicolumn{7}{|l|}{ ESR } \\
\hline$<20 \mathrm{~mm} / \mathrm{h}$ & 1 & & & & & \\
\hline$\geq 20 \mathrm{~mm} / \mathrm{h}$ & 0.745 & $(0.436-1.274)$ & 0.282 & & & \\
\hline \multicolumn{7}{|l|}{ CRP } \\
\hline$<0.5 \mathrm{mg} / \mathrm{dl}$ & 1 & & & & & \\
\hline$\geq 0.5 \mathrm{mg} / \mathrm{dl}$ & 0.669 & $(0.398-1.122)$ & 0.128 & & & \\
\hline \multicolumn{7}{|l|}{ ANA } \\
\hline Negative & 1 & & & & & \\
\hline Positive & 1.733 & $(0.920-3.268)$ & 0.089 & & & \\
\hline
\end{tabular}

ESR, erythrocyte sedimentation rate; CRP, C-reactive protein; ANA, anti-nuclear antibody.

old). However, there were no significant differences in disease duration with respect to gender or age $(P=0.697$ and $P=0.092$, respectively) (Table 2). In addition, no differences were found in CU prognosis according to the presence of angioedema, past medical history, family history of allergic diseases, or laboratory findings such as total IgE level, eosinophilia, ESR, CRP level, or ANA status.

Multivariable analysis also showed that allergic sensitization was associated with the persistence of CU $(P=0.014)$, and a trend for an association between the presence of inducible factors and remission was seen $(P=0.081)$ (Table 2). There were no differences between patients who went into remission and those that did not with respect to gender, age, the presence of angioedema, past medical history, family history of allergic diseases, or laboratory findings.

\section{Discussion}

In our present study, we found that half of children with $\mathrm{CU}$ achieved remission at 10.2 months after disease onset. Overall, $33.4 \%, 53.0 \%$, and $71.2 \%$ of patients achieved remission within 6,12 , and 24 months of disease onset. In addition, the symptoms of about $75 \%$ of subjects improved in response to avoiding inducible factors or taking a regular dose of $\mathrm{H} 1$ antihistamines, indicating a good response to conservative or 
medical treatment. To our knowledge, this is the largest study to describe the natural course and prognostic factors of $\mathrm{CU}$ in Korean children. The percentages of patients in remission at different time points in the present study are inconsistent with those reported in previous studies. ${ }^{15-20}$ Kang et al. reported a remission rate of $84.8 \%$ in Korean children with $\mathrm{CU}$ at the 1 year follow-up, which is a better prognosis than what we found in our study. ${ }^{15}$ However, previous studies conducted in other countries reported poorer outcomes than those of our study and Kang et al's study. For example, a Turkish study reported that $16.5 \%, 38.8 \%$, and $50.0 \%$ of children with CSU showed an improvement in symptoms within 1 year, 3 years, and 5 years after disease onset, respectively. ${ }^{20}$ In Japanese and Thai studies, symptoms improved in $36.6 \%$ and $18.5 \%$ of patients, respectively, within 1 year. ${ }^{16,18}$

Disagreement among studies on the natural course of CU might be due to differences in the study population and the presence of inducible factors. In particular, a younger age is likely to be associated with a better prognosis. ${ }^{15,20}$ In our study, the median age of patients was 5 years old, which is younger than the 8-9 years described in previous studies. ${ }^{18-20}$ In addition, gender might affect the prognosis of $\mathrm{CU}$, because sex hormones are involved in the action of mast cells, peripheral basophil cells, and dendritic cells. ${ }^{4,21}$ In our study, the male to female ratio was 1.3: 1 , which is a higher male predominance than in other studies. ${ }^{18,22}$ According to previous reports, 50$80 \%$ of CU patients have CSU, and only $25-40 \%$ of CU patients have inducible factors, of which physical urticaria is the most common. ${ }^{22-24}$ In our study, $31.2 \%$ of the patients did not have any cause of urticaria, despite detailed history taking and several tests. The only cause of CIU was physical urticaria, and dermographism was the most common cause of physical urticaria, consistent with another domestic study that reported that $42.3 \%$ of CU patients have dermographism. ${ }^{15}$ In the present study, the proportion of CSU was lower than that reported in a previous study. ${ }^{15}$ We should note that our study included dermographism as an inducible CU factor, whereas previous studies did not.

Allergic sensitization was the only factor that was associated with a worse $\mathrm{CU}$ prognosis in our present study, although the importance of atopic status in the pathogenesis of CU is still a matter of debate. A previous Korean study showed that children with CU had a higher prevalence of sensitization against house dust mites and polysensitization compared to those with acute urticaria. ${ }^{25}$ Several previous studies have reported a higher prevalence of sensitization to variable allergens in patients with $\mathrm{CU}$ than in normal healthy subjects, ${ }^{26-28}$ while fewer studies have investigated the association between atopy and CU prognosis. Recently, Song et al. reported that house dust mite sensitization as well as a positive autologous serum skin test (ASST) result were related to more severe disease and a longer disease duration. ${ }^{26}$ Furthermore, higher expression of CD63 was observed in basophils from patients with CSU, suggesting that spontaneous basophil activation may contribute to the relationship between CU and allergic sensitization. ${ }^{29}$

The presence of inducible factors and/or autoimmune antibodies have been considered poor prognostic factors in previous studies of patients with CU, although this is still controversial. ${ }^{15,22,23}$ We found a trend for an association between the presence of inducible factors and remission without statistical significance in the multivariable analysis. A previous study found that symptom duration was longer in autoimmune urticaria, which was defined in that study as positive ASST, than $\mathrm{CSU}^{23}$ In that study, $17 \%$ of patients with CU were ANA positive, and $16 \%$ and $12 \%$ of patients were positive for anti-thyroglobulin antibodies and anti-microsomal antibodies, respectively. ${ }^{23}$ These autoantibodies could activate basophils and mast cells to induce histamine release by complement. ${ }^{30}$ In our present study, the ANA-positive rate was $25.0 \%$, which is higher than that reported previously for healthy children (6-14\%). ${ }^{31,32}$ However, we did not find an association between $\mathrm{CU}$ prognosis and autoimmune diseases, because the number of patients who received tests for autoantibodies was too small for robust statistical evaluation of this relationship. Further studies are required to identify additional prognostic factors in children with CU.

Our study had some limitations that must be considered. This study was performed in a single tertiary center, therefore selection bias might have occurred. Secondly, remission state was determined by telephone survey for some patients because of the retrospective nature of the study. There might be patients with persistent disease who were selectively missed, although the telephone survey was done with all caregivers whose children were lost to follow-up. In addition, the same laboratory tests were not performed in all patients. Therefore, some variables such as CRP and ANA were not included in the multivariable analysis. It also should be noted that the treatment in our present study followed Korean Expert Opinion Report on the Management of CU, not international guidelines. ${ }^{6}$ Despite these limitations, we provide useful information regarding the natural course of CU in children, the response rates to medical treatment, and prognostic factors.

In conclusion, the median duration of CU in Korean children was 10.2 months, and half of the CU patients showed symptom improvement within a year, indicating that children with CU had a favorable outcome. Allergic sensitization was associated with a poor CU prognosis.

\section{References}

1. Khakoo G, Sofianou-Katsoulis A, Perkin MR, Lack G. Clinical features and natural history of physical urticaria in children. Pediatr Allergy Immunol. 2008;19:363-6.

2. Beattie PE, Lewis-Jones MS. A comparative study of impairment of quality of life in children with skin disease and children with other chronic childhood diseases. Br J Dermatol. 2006;155:145-51.

3. O'Donnell BF. Urticaria: impact on quality of life and economic cost. Immunol Allergy Clin North Am. 2014;34:89-104.

4. Chen W, Mempel M, Schober W, Behrendt H, Ring J. Gender difference, sex hormones, and immediate type hypersensitivity reactions. Allergy. 2008;63:1418-27.

5. Zuberbier T, Balke M, Worm M, Edenharter G, Maurer M. Epidemiology of urticaria: a representative cross-sectional population survey. Clin Exp Dermatol. 2010;35:869-73.

6. Ye YM, Jang GC, Choi SH, Lee J, Yoo HS, Park KH, et al. KAAACI Work Group report on the management of chronic urticaria. Allergy Asthma Respir Dis. 2015;3:3-14.

7. Radonjic-Hoesli S, Hofmeier KS, Micaletto S, Schmid-Grendelmeier P, Bircher A, Simon D. Urticaria and Angioedema: an Update on Classification and Pathogenesis. Clin Rev Allergy Immunol. 2018; 54(1):88-101.

8. Tannert LK, Skov PS, Jensen LB, Maurer M, Bindslev-Jensen C. Cold urticaria patients exhibit normal skin levels of functional mast cells and histamine after tolerance induction. Dermatology. 2012;224(2):101-5. 
9. Maurer M, Metz M, Brehler R, Hillen U, Jakob T, Mahler V, et al. Omalizumab treatment in patients with chronic inducible urticaria: A systematic review of published evidence. J Allergy Clin Immunol. 2018; 141(2):638-49.

10. Maurer M, Weller K, Bindslev-Jensen C, Gimenez-Arnau A, Bousquet PJ, Bousquet J, et al. Unmet clinical needs in chronic spontaneous urticaria. A GA(2)LEN task force report. Allergy 2011;66:317-30.

11. Kim S, Baek S, Shin B, Yoon SY, Park SY, Lee T, et al. Influence of initial treatment modality on long-term control of chronic idiopathic urticaria. PLoS One. 2013;8:e69345.

12. Toubi E, Kessel A, Avshovich N, Bamberger E, Sabo E, Nusem D. Clinical and laboratory parameters in predicting chronic urticaria duration: a prospective study of 139 patients. Allergy. 2004;59:869-73.

13. Ye YM, Park JW, Kim SH, Ban GY, Kim JH, Shin YS, et al. Prognostic factors for chronic spontaneous urticaria: A 6-month prospective observational study. Allergy Asthma Immunol Res. 2016;8:115-23.

14. Bernstein JA, Lang DM, Khan DA, Craig T, Dreyfus D, Hsieh F, et al. The diagnosis and management of acute and chronic urticaria: 2014 update. J Allergy Clin Immunol. 2014;133:1270-7.

15. Kang HS, Shin MY. Clinical aspects of chronic urticaria in children. Korean J Pediatr. 2009;52:205-12.

16. Hiragun M, Hiragun T, Mihara S, Akita T, Tanaka J, Hide M. Prognosis of chronic spontaneous urticaria in 117 patients not controlled by a standard dose of antihistamine. Allergy. 2013;68:229-35.

17. Kozel MM, Mekkes JR, Bossuyt PM, Bos JD. Natural course of physical and chronic urticaria and angioedema in 220 patients. J Am Acad Dermatol. 2001;45:387-91.

18. Chansakulporn S, Pongpreuksa S, Sangacharoenkit P, Pacharn P, Visitsunthorn N, Vichyanond $\mathrm{P}$, et al. The natural history of chronic urticaria in childhood: a prospective study. J Am Acad Dermatol. 2014;71:663-8.

19. Jirapongsananuruk O, Pongpreuksa S, Sangacharoenkit P, Visitsunthorn $\mathrm{N}$, Vichyanond P. Identification of the etiologies of chronic urticaria in children: a prospective study of 94 patients. Pediatr Allergy Immunol. 2010;21:508-14

20. Sahiner UM, Civelek E, Tuncer A, Yavuz ST, Karabulut E, Sackesen C, et al. Chronic urticaria: etiology and natural course in children. Int Arch Allergy Immunol. 2011;156:224-30.
21. Zierau O, Zenclussen AC, Jensen F. Role of female sex hormones, estradiol and progesterone, in mast cell behavior. Front Immunol. 2012;3:169.

22. Silpa-archa N, Kulthanan K, Pinkaew S. Physical urticaria: prevalence, type and natural course in a tropical country. J Eur Acad Dermatol Venereol. 2011;25:1194-9.

23. Kulthanan K, Jiamton S, Thumpimukvatana N, Pinkaew S. Chronic idiopathic urticaria: prevalence and clinical course. J Dermatol. 2007;34: 294-301.

24. Caffarelli C, Cuomo B, Cardinale F, Barberi S, Dascola CP, Agostinis F, et al. Aetiological factors associated with chronic urticaria in children: a systematic review. Acta Derm Venereol. 2013;93:268-72.

25. Lee JB, Lee SH, Han MY, Yoon JW. Allergen sensitization and vitamin D status in young Korean children with urticaria. Allergy Asthma Respir Dis. 2017;5:153-8.

26. Song Z, Zhai Z, Zhong H, Zhou Z, Chen W, Hao F. Evaluation of autologous serum skin test and skin prick test reactivity to house dust mite in patients with chronic spontaneous urticaria. PLoS One. 2013;8:e64142.

27. Gecer E, Erdem T. Aeroallergen prick skin test and autologous serum skin test results in patients with chronic urticaria and their comparison. Ann Dermatol. 2012;24:472-4.

28. Bains P, Dogra A. Skin Prick Test in Patients with Chronic Allergic Skin Disorders. Indian J Dermatol. 2015;60:159-64.

29. Chen Q, Zhai Z, Xu J, Chen W, Chen S, Zhong H, et al. Basophil CD63 expression in chronic spontaneous urticaria: correlation with allergic sensitization, serum autoreactivity and basophil reactivity. J Eur Acad Dermatol Venereol. 2017;31:463-8.

30. Kaplan AP, Greaves M. Pathogenesis of chronic urticaria. Clin Exp Allergy. 2009;39:777-87.

31. Satoh M, Chan EK, Ho LA, Rose KM, Parks CG, Cohn RD, et al. Prevalence and sociodemographic correlates of antinuclear antibodies in the United States. Arthritis Rheum. 2012;64:2319-27.

32. Guo YP, Wang CG, Liu X, Huang YQ, Guo DL, Jing XZ, et al. The prevalence of antinuclear antibodies in the general population of china: a cross-sectional study. Curr Ther Res Clin Exp. 2014;76:116-9. 